\title{
backstory
}

\section{Bed of ice}

\section{Edward King and colleagues towed a radar system over Antarctic ice, and whiled away Christmas in a tent, in their quest to understand glacier sliding.}

What was the objective of the work? Our aim was to understand how large Antarctic glaciers can slide into the ocean at speeds of one metre per day or more. Understanding this process is fundamental to predicting how much more ice may end up in the ocean in a changing climate, and the extent to which sea levels are likely to rise. In this particular project, we wanted to determine the properties and morphology of sediments at the bed of Rutford Ice Stream, a glacier in West Antarctica, that promote rapid ice flow.

\section{Why did you choose this particular} location for the fieldwork?

The British Antarctic Survey has visited Rutford Ice Stream many times, building an excellent understanding of the basic features of the glacier. Recently, the seismic survey team made the surprising discovery that the properties and shape of the bed of the ice stream can change very rapidly - they observed significant erosion and deposition over a 13-year period. However, there was a need to place the seismic data in a three-dimensional context, as we knew little about the threedimensional form of the features on the bed. So we took a radar system to the same area to investigate.

\section{What sorts of data were you after?} We wanted to survey the thickness of the ice, together with the reflection characteristics of the glacier bed, in as much detail as possible. We used a radar system to record the time-of-flight of a low-frequency radio pulse from the surface to the bed and back again: from this we derived ice thickness and bed characteristics. We carried out 35 profiles

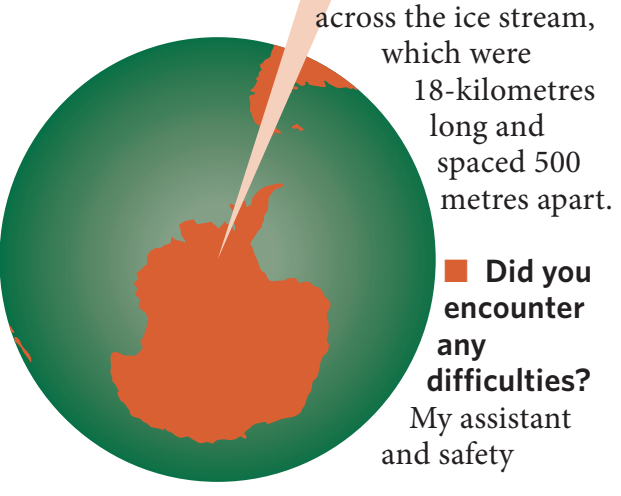

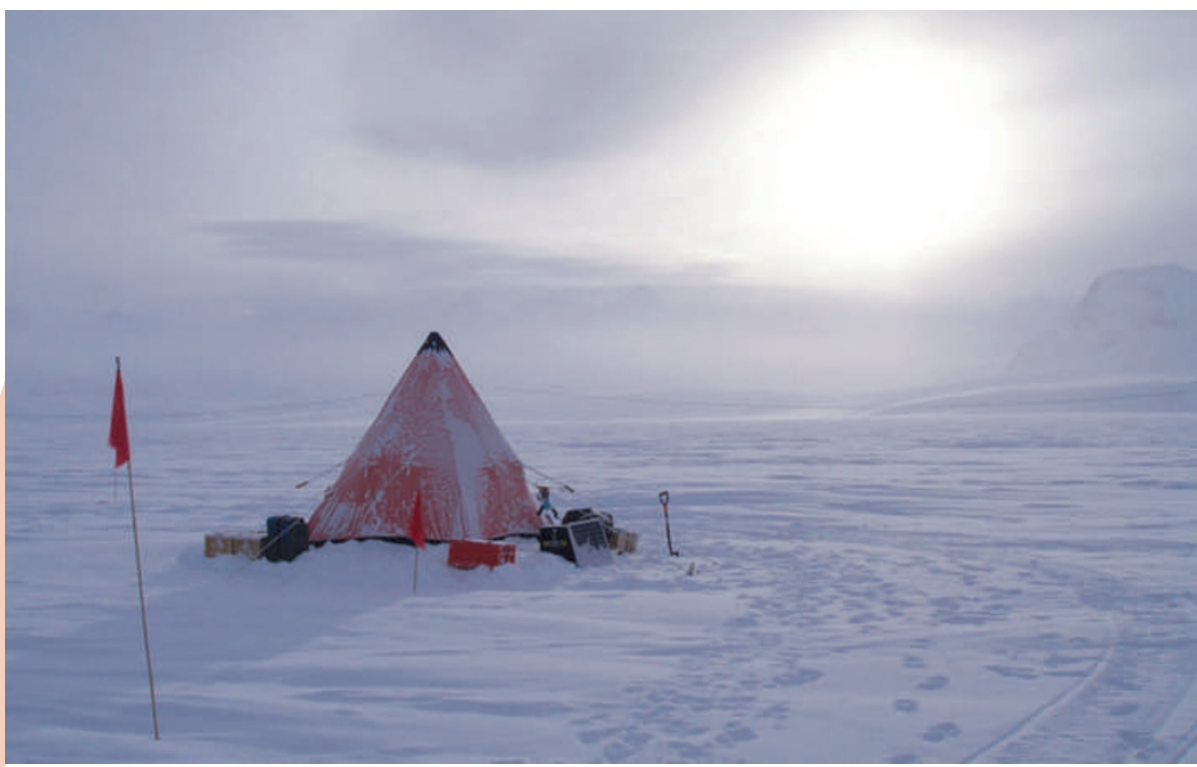

The tent in which Edward King and his companion camped for two months at temperatures down to $-30^{\circ} \mathrm{C}$

officer, Roger Stilwell, and I flew 1,000 kilometres from our base on the coast to reach the glacier. We arrived in mid-November, which is spring in Antarctica. The temperature was around -25 to $-30^{\circ} \mathrm{C}$, a serious test for both us and the equipment. We towed the radar system by snowmobile, which provided little protection from wind chill. So we dressed in many layers for insulation, and made sure no flesh was at risk of frostbite. But the cold seeps in and, even with great scenery, driving for hours on end in a straight line gets pretty boring. I started thinking about developing a robot to do the job! We took turns to do the cooking, which is a challenge with only one kerosene stove available. But with a little invention it was possible to produce delicacies such as pizza cooked in a frying pan.

\section{Any low points?}

The low points were sitting out a fourday storm in our 2.2-metre-square tent, and being away from my family for yet another Christmas. Even though we decorated the tent and opened presents brought from home back in October, it's just not the same.
What was the highlight of the expedition?

The scientific highlight came when I first plotted the bed elevation data in map form, which showed a beautiful image of the landscape two kilometres below our feet. The personal highlight was seeing a full set of parhelia for the first time. These bright sunspots, caused by tiny ice crystals, filled the sky with multiple haloes and sun pillars; it was a wonderful and uplifting sight.

\section{How did you get back to base?}

At the end of our season, when we finally saw a tiny dot coming towards us over the ice and heard the sound of an approaching aircraft, I had very mixed thoughts and emotions. Relief that the journey home was about to start; regret that this might be the last time I see such a fantastically beautiful landscape; satisfaction that I'd collected such a good dataset; and a feeling of being very small in a very big space. But such deep thinking was pushed aside when the pilot offered me a fresh apple.

This is the Backstory to the work by Edward King and colleagues, published on page 585 of this issue. 